\title{
Fracture risk in patients with type 2 diabetes under different antidiabetic treatment regimens: a retrospective database analysis in primary care
}

This article was published in the following Dove Press journal:

Diabetes, Metabolic Syndrome and Obesity:Targets and Therapy

19 February 2016

Number of times this article has been viewed

\author{
S Pscherer' \\ K Kostev ${ }^{2}$ \\ FW Dippel ${ }^{3}$ \\ W Rathmann ${ }^{4}$ \\ 'Department of Diabetology, Klinikum \\ Traunstein, Kliniken Südostbayern \\ AG, Traunstein, ${ }^{2}$ Epidemiology \\ Department, IMS Health, Frankfurt, \\ ${ }^{3}$ Sanofi-Aventis Deutschland \\ $\mathrm{GmbH}$, Berlin, ${ }^{4}$ German Diabetes \\ Center, Institute for Biometrics and \\ Epidemiology, Leibniz Center for \\ Diabetes Research at Heinrich Heine \\ University, Düsseldorf, Germany
}

Aim: Type 2 diabetes is associated with an increased risk of fractures. There are a few studies on the effects of diabetes treatment on fracture risk. The aim was to investigate the fracture risk related to various types of insulin therapy in primary care practices.

Methods: Data from 105,960 type 2 diabetes patients from 1,072 general and internal medicine practices in Germany were retrospectively analyzed (Disease Analyzer database; 01/2000-12/2013). Fracture risk of the following therapies was compared using multivariate logistic regression models adjusting for age, sex, diabetes care, comorbidity, and glycemic control $\left.\left(\mathrm{HbA}_{\mathrm{lc}}\right): 1\right)$ incident insulin therapy versus oral antidiabetic drugs, 2) basal-supported oral therapy versus supplementary insulin therapy versus conventional insulin therapy, and 3) insulin glargine versus insulin detemir versus NPH insulin.

Results: There was a lower odds of having incident fractures in the oral antidiabetic drug group compared to incident insulin users, although not significant (odds ratio [OR]; 95\% confidence interval: $0.87 ; 0.72-1.06)$. There were increased odds for conventional insulin therapy (OR: 1.59; 95\% CI [confidence interval] 0.89-2.84) and supplementary insulin therapy (OR: 1.20; 0.63-2.27) compared to basal-supported oral therapy, which was not significant as well. Overall, there was no significant difference in fracture risk for basal insulins (glargine, detemir, NPH insulin). After a treatment duration $\geq 2$ years, insulin glargine showed a lower odds of having $\geq 1$ fracture compared to NPH users (OR: 0.78; 0.65-0.95) (detemir vs NPH insulin: OR: 1.03; 0.79-1.36).

Conclusion: Long-standing therapy with insulin glargine was associated with a lower odds of having any fractures compared to NPH insulin. Further studies are required to investigate whether the lower chance is due to a reduced frequency of hypoglycemia.

Keywords: type 2 diabetes, fracture risk, insulin treatment, oral antidiabetic medication, primary care

\section{Introduction}

There is evidence that type 2 diabetes is associated with an increased risk of fractures. ${ }^{1-4}$ Antidiabetic medication may modify fracture risk in patients with type 2 diabetes. ${ }^{5}$ Several observational studies have indicated that insulin treatment is related to an increased risk of fractures. ${ }^{6-8}$ The relationship between insulin treatment and fracture risk may be mediated by hypoglycemic events and an increased risk of falls. ${ }^{9}$ However, observational studies of the effects of drugs are prone to bias, which often results in conflicting results. ${ }^{10}$ For example, a case-control study from Denmark found that use of insulin was associated with a reduced risk of any fractures in diabetes patients. ${ }^{11}$ A stratified analysis for different types of insulin therapy (eg, basal-supported oral therapy [BOT], conventional insulin therapy [CT], or prandial insulin therapy) has not being carried out so far. ${ }^{11}$
Correspondence: $\mathrm{K}$ Kostev Epidemiology and Evidence Based Medicine, Epidemiology Department, IMS Health, Darmstädter Landstraße 10860598 Frankfurt am Main, Germany Tel +49696604 4878

Email kkostev@de.imshealth.com
Diabetes, Metabolic Syndrome and Obesity:Targets and Therapy 20।6:9 I7-23

Dovepress

http://dx.doi.org/10.2147/DMSO.S101370 (c) (1) (5) 2016 Pscherer et al. This work is published and licensed by Dove Medical Press Limited. The full terms of this license are available at httpss://www.dovepress.com/terms. (c) 1 SC
you hereby accept the Terms. Non-commercial uses of the work are permitted without any further permission from Dove Medical Press Limited, provided the work is properly attributed. For you hereby accept the Terms. Non-commercial uses of the work are permitted without any further permission from Dove Medical Press
permission for commercial use of this work, please see paragraphs 4.2 and 5 of our Terms (https://www.dovepress.com/terms.php). 
Thus, there is a need for further longitudinal studies on the relationship between insulin treatment and incidence of fractures in type 2 diabetes. For the present study, longitudinal data from general practices throughout Germany were used (German Disease Analyzer database) (IMS Health, Frankfurt, Germany). The aim was to compare the risk of fractures in type 2 diabetes patients on insulin compared to patients on other antidiabetic medication (oral drugs including injectables, such as GLP-1 receptor agonists). In addition, fracture risk of various types of insulin therapy, including BOT, supplementary insulin therapy (SIT), and CT, was compared. Finally, fracture risk in users of different types of basal insulins (insulin detemir, insulin glargine, NPH insulin) was assessed.

\section{Methods}

\section{Study population}

The German Disease Analyzer database includes patient data entered by general practitioners throughout Germany. ${ }^{12,13}$ Practices anonymously report all diagnoses International Statistical Classification of Diseases and Related Health Problems- 10th Revision (ICD-10), prescriptions (Anatomical Therapeutic Chemical Classification System), hospital admissions, and laboratory test results on an ongoing basis. The validity and representativeness of the Disease Analyzer database have been assessed previously. ${ }^{14}$

The current study sample included 105,960 type 2 diabetes patients from 1,072 practices who received $\geq 1$ insulin prescription per 180 days during the index period used for this study (January 2000 to August 2014). Patients were excluded from the study when they had diagnosed osteoporosis (ICD-10: M81) or a related treatment (Anatomical Therapeutic Chemical: M05B) recorded at baseline. Further exclusion criteria were bone metastases (ICD-10: C795) and diseases which could have altered bone mineral density (ICD-10: M83-85). Finally, patients with cerebrovascular diseases, including stroke (ICD-10: I60-69), dementia (ICD10: F01, F03, G30), visual disturbances (ICD-10: H53-54), Morbus Paget (ICD-10: M88), and with glucocorticoid or thiazolidinedione prescriptions were excluded. Patients were also excluded from analyses when a first diagnosis of any fracture was prior to the first insulin prescription.

The primary outcome was fracture incidence (ICD-10: M80, S02, S12, S22, S32, S42, S52, S62, S72, S82, S92, $\mathrm{T} 02, \mathrm{~T} 08, \mathrm{~T} 10, \mathrm{~T} 12)$ recorded in the database between the index date of first recorded insulin prescription and end of follow-up.

Demographic data included age, sex, health insurance (private/statutory health insurance), diabetes duration, and diabetologist care. Obesity diagnosis, lipid disorders, hypertension, macrovascular complications (coronary heart disease, myocardial infarction, peripheral vascular disease), and prevalence of microvascular complications (retinopathy, neuropathy, nephropathy) were assessed as potential confounders. Obesity diagnosis most likely reflects severe or morbid obesity. Baseline data on body mass index (BMI) and $\mathrm{HbA}_{\mathrm{lc}}$ were only available for a subgroup (BMI: $\mathrm{n}=26,490 ; 25.0 \%$; $\mathrm{HbA}_{\mathrm{lc}}$ : $\mathrm{n}=70,920 . . ; 66.9 \%$ ). Furthermore, a revised version of the Charlson comorbidity score was used as a generic marker of comorbidity. ${ }^{15}$ Covariates were assessed before the start of antidiabetic therapy (mean duration: 2.8 years).

\section{Statistical methods}

Descriptive statistics were given and differences in characteristics of patients (oral antidiabetic drug [OAD] vs insulin; different insulin regimens) were assessed using Student's $t$-tests, Wilcoxon rank sum tests, chi-square, or Kruskal-Wallis tests. Logistic regression models (dependent variable: incident fracture) were used to adjust for age, sex, diabetes duration, diabetologist care, and comorbidity. A final multivariate logistic regression model was fitted using stepwise regression. The level of statistical significance was 5\%. The analyses were carried out using SAS version 9.3. Since analysis of anonymous data was performed, this study was exempted from institutional ethical review board oversight. The analysis was carried out following established nationa ${ }^{16}$ and international good practice recommendations for secondary data analysis. ${ }^{17}$

\section{Results}

\section{Fracture risk in newly prescribed insulin therapy versus OADs}

After applying the above-mentioned exclusion criteria, 24,250 type 2 diabetes patients with incident insulin therapy were included in the analyses. The mean follow-up after first insulin prescription until incidence of fracture or end of observation was 2.0 years. Overall, 842 (3.5\%) patients experienced $\geq 1$ fracture documented in the practice records after onset of insulin therapy (Table 1). As a control group, 81,710 type 2 diabetes patients without insulin prescriptions were included who received any OAD during the observation period (mean follow-up: 2.5 years). There were 3,508 (4.3\%) patients with $\geq 1$ fracture among OAD users.

Patients with first insulin prescription were older, had more often microvascular complications of diabetes, and were more frequently in diabetologist care than OAD users (Table 1). OAD treated patients had more often a diagnosis of hypertension, dyslipidemia, obesity, and depression than 
Table I Baseline characteristics of primary care patients with incident insulin therapy or oral antidiabetic drug (OAD) treatment (Disease Analyzer database, IMS Health, Frankfurt, Germany)

\begin{tabular}{lll}
\hline Variables & OAD & Insulin \\
\hline $\mathrm{N}$ & 81,710 & 24,250 \\
Age (years) & $63.1(12.4)^{*}$ & $66.4(13.9)^{*}$ \\
Male sex (\%) & $54.3^{*}$ & $51.9^{*}$ \\
Diabetes duration (years) & $0.8(1.8)^{*}$ & $0.7(1.8)^{*}$ \\
Private health insurance (\%) & $7.0^{*}$ & $4.2^{*}$ \\
Diabetologist care (\%) & $15.4^{*}$ & $43.1^{*}$ \\
Baseline diagnoses & & \\
Hypertension (\%) & $62.4^{*}$ & $46.9^{*}$ \\
Hyperlipidemia (\%) & $34.6^{*}$ & $21.0^{*}$ \\
Obesity (\%) & $19.0^{*}$ & $11.9^{*}$ \\
Myocardial infarction (\%) & $4.2^{*}$ & $5.1^{*}$ \\
Coronary heart disease (\%) & $16.1^{*}$ & $17.5^{*}$ \\
Peripheral vascular disease (\%) & $4.9^{*}$ & $10.7^{*}$ \\
Peripheral neuropathy (\%) & $4.7^{*}$ & $14.4^{*}$ \\
Retinopathy (\%) & $1.3^{*}$ & $5.7^{*}$ \\
Nephropathy (\%) & $4.9^{*}$ & $13.8^{*}$ \\
Heart failure (\%) & $5.9^{*}$ & $8.0^{*}$ \\
Depression (\%) & $9.4^{*}$ & $4.7^{*}$ \\
Charlson Comorbidity Score & $1.3(0.8)^{*}$ & $1.7(1.1)^{*}$ \\
HbA ${ }_{\mathrm{lc}} \%$ (baseline) & $7.5(\mathrm{I} .6)^{*}$ & $8.2(2.0)^{*}$ \\
Body mass index (kg/m ${ }^{2}$ ) (baseline) & $31.7(5.6)^{*}$ & $30.1(5.9)^{*}$ \\
\hline
\end{tabular}

Notes: Data are mean (standard deviation) or proportions (\%). $* P<0.05$ OAD versus insulin.

insulin users (Table 1). There were no substantial differences in prevalence of macrovascular complications between the two groups, except for peripheral vascular disease, which was more often found among insulin users. Finally, baseline $\mathrm{HbA}_{\mathrm{lc}}$ was higher among patients who started insulin, whereas BMI was slightly increased among OAD users (Table 1).

Compared to patients with newly prescribed insulin therapy, there was a lower odds of fractures in patients with $\mathrm{OAD}$, although not statistically significant. In a final model (stepwise selection), the corresponding odds ratio for having $\geq 1$ fracture was 0.87 (95\% confidence interval: $0.72 ; 1.06$ ) for OAD versus insulin use (Table 2). An increased odds of having any fractures was found for higher age, heart failure,

Table 2 Multivariate logistic regression model for developing any fractures in type 2 diabetes patients in primary care practices

\begin{tabular}{lll}
\hline Variables & $\begin{array}{l}\text { Odds ratio } \\
\text { (95\% Cl) }\end{array}$ & P-value \\
\hline OAD versus insulin treatment & $0.87(0.72-1.06)$ & 0.1744 \\
Age (year) & $1.04(1.03-1.05)$ & $<0.000$ I \\
Male sex (yes/no) & $0.59(0.50-0.69)$ & $<0.0001$ \\
Diabetologist care (yes/no) & $0.32(0.24-0.43)$ & $<0.0001$ \\
Heart failure (yes/no) & $1.31(1.02-1.67)$ & 0.0330 \\
Peripheral arterial disease (yes/no) & $1.48(1.11-1.95)$ & 0.0069 \\
\hline
\end{tabular}

Note: Final model after stepwise selection of all variables.

Abbreviations: $\mathrm{Cl}$, confidence interval; OAD, oral antidiabetic drug (including GLP-I-based therapies). and peripheral arterial disease in the multivariable model. Diabetologist care was significantly related to a lower odds of fractures (Table 2). Finally, men showed a lower chance of having fractures compared to women with type 2 diabetes.

\section{Fracture risk in BOT, CT, and SIT}

In the observation period, there were 15,852 prevalent insulin users with BOT, 10,995 with CT, and 14,542 with SIT, respectively (Table 3 ). The CT group was older, comprised more females, and had a shorter diabetes duration in the practices than the other two cohorts (BOT, SIT). Forty-two percent of SIT users were in diabetologist care, which was higher than in the other groups. Hypertension was frequently documented in all insulin regimens, whereas prevalence of hyperlipidemia and obesity was the highest in the BOT patients. No difference was observed for prevalence of myocardial infarction between the three groups. Frequency of microvascular complications was also comparable except for nephropathy, which was more often found in BOT users who also had the highest proportion of concomitant hypertension. Average $\mathrm{HbA}_{\mathrm{lc}}$ and BMI were similar in all insulin groups as well as a low prevalence of patients with documented hypoglycemia. As expected, comedication with oral antidiabetic agents and GLP-1-based drugs was the highest in the BOT cohort.

The mean follow-up times were 1.5 years in BOT, 1.8 years in CT, and 0.9 years in SIT users, respectively. There were $601(3.8 \%)$ patients with fractures among BOT users (CT: $n=633,5.8 \%$; SIT: $n=508,3.5 \%)(P<0.0001)$. There was an indication that $\mathrm{CT}$ users had a higher chance of any fractures compared to the BOT regimen which, however, was not statistically significant in multivariable analysis (Table 4). There was no increased OR for SIT users (reference: BOT). Age was related to an increased odds, whereas male sex and diabetologist care were both related to a lower chance of fractures. Finally, comedication with sulfonylureas was related to a higher odds of fractures.

\section{Fracture risk among basal insulin users}

There were 5,408 type 2 diabetes patients using insulin glargine in the observation period (detemir: $\mathrm{n}=1,569$; NPH insulin: $n=6,762$ ). The mean follow-up in insulin glargine users was 1.7 years (detemir: 1.7 years; NPH: 2.0 years). There were $708(4.1 \%)$ patients on glargine treatment who experienced at least one fracture during the study period (detemir: $\mathrm{n}=184,3.6 \%$; NPH: $\mathrm{n}=698,3.8 \%$ ).

Insulin glargine-treated patients were slightly older than detemir and NPH users (Table 5). Diabetes duration recorded in the practices was somewhat longer in glargine 
Table 3 Baseline characteristics of insulin-treated type 2 diabetes primary care patients with BOT, CT, or SIT (Disease Analyzer database, IMS Health, Frankfurt, Germany)

\begin{tabular}{|c|c|c|c|c|}
\hline Variables & BOT & CT & SIT & $P$-value \\
\hline $\mathrm{N}$ & 15,852 & 10,995 & 14,542 & - \\
\hline Age (years) & $64.1(15.5)$ & $71.8(11.4)$ & $62.3(13.5)$ & $<0.0001$ \\
\hline Male sex (\%) & 54.4 & 44.2 & 54.5 & $<0.000$ I \\
\hline Diabetes duration (years) & $1.6(2.5)$ & $0.8(1.9)$ & $1.0(2.1)$ & $<0.000$ I \\
\hline Private health insurance (\%) & 5.8 & 3.6 & 4.2 & $<0.0001$ \\
\hline Diabetologist care (\%) & 37.2 & 28.9 & 42.1 & $<0.000$ I \\
\hline \multicolumn{5}{|l|}{ Baseline diagnoses } \\
\hline Hypertension (\%) & 56.8 & 51.5 & 47.1 & $<0.0001$ \\
\hline Hyperlipidemia (\%) & 32.0 & 21.7 & 23.2 & $<0.000$ I \\
\hline Obesity (\%) & 20.0 & 11.6 & 16.6 & $<0.000$ I \\
\hline Myocardial infarction (\%) & 5.0 & 5.1 & 4.6 & 0.1513 \\
\hline Coronary heart disease (\%) & 17.7 & 20.4 & 14.8 & $<0.0001$ \\
\hline Peripheral vascular disease (\%) & 9.6 & 10.0 & 9.0 & 0.0318 \\
\hline Peripheral neuropathy (\%) & 14.3 & 11.9 & 13.4 & $<0.000$ I \\
\hline Retinopathy (\%) & 4.6 & 3.8 & 5.2 & $<0.000$ I \\
\hline Nephropathy (\%) & 19.8 & 10.9 & 9.8 & 0.0046 \\
\hline Heart failure (\%) & 8.0 & 11.4 & 5.7 & $<0.0001$ \\
\hline Depression (\%) & 7.7 & 6.1 & 5.4 & $<0.000$ I \\
\hline Charlson Comorbidity Score & $1.6(1.1)$ & $1.6(1.1)$ & $1.6(1.1)$ & 0.0042 \\
\hline $\mathrm{HbA}_{\mathrm{lc}}(\%)$ (baseline) & $8.6(1.9)$ & $8.4(1.9)$ & $8.4(2.1)$ & $<0.000$ I \\
\hline Body mass index $\left(\mathrm{kg} / \mathrm{m}^{2}\right)$ (baseline) & $31.4(5.7)$ & $30.4(5.4)$ & $31.4(6.0)$ & $<0.0001$ \\
\hline Documented hypoglycemia (\%) & I.I & 0.9 & 1.4 & 0.0003 \\
\hline \multicolumn{5}{|l|}{ Comedication (\%) } \\
\hline Metformin & 68.4 & 22.3 & 21.4 & $<0.000$ I \\
\hline Sulfonylurea & 19.7 & 8.1 & 3.0 & $<0.000$ I \\
\hline DPP-4 inhibitors & 18.0 & 3.5 & 3.3 & $<0.0001$ \\
\hline GLP-I receptor agonists & 3.9 & 0.3 & 0.8 & $<0.0001$ \\
\hline
\end{tabular}

Notes: Data are mean (standard deviation) or proportions (\%). P-value: Kruskal-Wallis tests.

Abbreviations: BOT, basal-supported oral therapy; CT, conventional insulin therapy; SIT, supplementary insulin therapy.

and detemir users than in the NPH group. Patients with NPH basal insulin were more frequently treated in diabetologist care than the other two groups (Table 5). The prevalence of macrovascular complications and related risk factors (hypertension, hyperlipidemia) was comparable for the three treatment regimens. Microvascular complications (retinopathy, neuropathy) were more frequently recorded in the detemir and NPH cohorts than in glargine users

Table 4 Multivariate logistic regression model for developing any fractures in type 2 diabetes patients in primary care practices

\begin{tabular}{lll}
\hline Variables & $\begin{array}{l}\text { Odds ratio } \\
(\mathbf{9 5 \%} \mathbf{C l})\end{array}$ & P-value \\
\hline CT versus BOT & $1.59(0.89-2.84)$ & 0.1194 \\
SIT versus BOT & $1.20(0.63-2.27)$ & 0.5834 \\
Age (year) & $1.03(1.00-1.05)$ & 0.0190 \\
Male sex (yes/no) & $0.48(0.29-0.79)$ & 0.0038 \\
Diabetologist care (yes/no) & $0.53(0.28-0.99)$ & 0.0463 \\
Sulfonylurea (yes/no) & $1.86(1.06-3.29)$ & 0.0320 \\
\hline
\end{tabular}

Note: Final model after stepwise selection of all variables.

Abbreviations: BOT, basal-supported oral therapy; $\mathrm{Cl}$, confidence interval; $\mathrm{CT}$, conventional insulin therapy; SIT, supplementary insulin therapy.
(Table 5). Finally, heart failure and depression were more often found in the glargine group.

Baseline BMI and prevalence of diagnosed obesity were high in all three groups. Average $\mathrm{HbA}_{\mathrm{lc}}$ levels were somewhat higher in glargine and detemir users, whereas prevalence of documented hypoglycemia was low in all three cohorts (Table 5). All basal insulin regimens were frequently treated with additional short acting insulins $(62 \%-81 \%)$. Sulfonylureas were more often prescribed in glargine users and DPP-4 inhibitors were less often used in the NPH group compared to the other two cohorts (Table 5).

Overall, there was no difference in fracture risk between various basal insulin users (glargine, detemir, NPH). There was an indication that treatment duration with basal insulin had an impact on fracture risk (data not shown). Therefore, only patients with a minimum basal insulin treatment duration of 2 years were included (Table 6). In these analyses, insulin glargine was related to a lower odds of having any fractures compared to NPH use (Table 6). No difference was observed between the detemir and NPH cohorts. Furthermore, male sex 
Table 5 Baseline characteristics of insulin-treated type 2 diabetes primary care patients with insulin glargine, detemir, and NPH insulin

\begin{tabular}{|c|c|c|c|c|}
\hline Variables & Glargine & Detemir & NPH & $P$ value \\
\hline $\mathrm{N}$ & 5,408 & $\mathrm{I}, 569$ & 6,762 & \\
\hline Age (years) & $65.5(12.1)$ & $62.4(12.0)$ & $63.9(11.6)$ & $<0.0001$ \\
\hline Male sex (\%) & 54.8 & 54.5 & 53.6 & 0.3934 \\
\hline Diabetes duration (years) & $2.0(2.7)$ & $1.9(2.7)$ & I.5 (2.3) & $<0.0001$ \\
\hline Private health insurance (\%) & 5.7 & 6.7 & 3.5 & $<0.0001$ \\
\hline Diabetologist care (\%) & 34.9 & 44.5 & 50.6 & $<0.0001$ \\
\hline \multicolumn{5}{|l|}{ Baseline diagnoses } \\
\hline Hypertension (\%) & 64.4 & 60.0 & 60.6 & $<0.0001$ \\
\hline Hyperlipidemia (\%) & 39.1 & 38.1 & 35.6 & 0.0003 \\
\hline Obesity (\%) & 19.5 & 22.2 & 19.7 & 0.0475 \\
\hline Myocardial infarction (\%) & 7.3 & 6.0 & 6.4 & 0.0625 \\
\hline Coronary heart disease (\%) & 23.2 & 20.5 & 20.3 & 0.0002 \\
\hline Peripheral vascular disease (\%) & 12.2 & 13.8 & 13.5 & 0.0644 \\
\hline Peripheral neuropathy (\%) & 16.8 & 20.9 & 19.4 & $<0.0001$ \\
\hline Retinopathy (\%) & 6.8 & 9.1 & 8.0 & 0.0030 \\
\hline Nephropathy (\%) & 14.3 & 13.1 & 11.5 & $<0.0001$ \\
\hline Heart failure (\%) & 10.2 & 7.1 & 8.6 & $<0.0001$ \\
\hline Depression (\%) & 9.7 & 8.7 & 7.5 & $<0.0001$ \\
\hline Charlson Comorbidity Score & $1.8(1.2)$ & $1.8(1.1)$ & $1.8(1.1)$ & 0.0984 \\
\hline $\mathrm{HbA}_{\mathrm{lc}} \%$ (baseline) & $8.5(1.8)$ & $8.6(1.9)$ & $8.2(1.7)$ & $<0.0001$ \\
\hline Body mass index $\left(\mathrm{kg} / \mathrm{m}^{2}\right)$ (baseline) & $30.8(5.7)$ & $32.0(6.0)$ & $31.8(5.9)$ & $<0.0001$ \\
\hline Documented hypoglycemia (\%) & 1.3 & 2.6 & 1.5 & 0.0025 \\
\hline \multicolumn{5}{|l|}{ Comedication (\%) } \\
\hline Short acting insulins & 61.2 & 78.9 & 81.1 & $<0.0001$ \\
\hline Metformin & 44.4 & 49.1 & 48.3 & $<0.0001$ \\
\hline Sulfonylurea & 19.5 & 12.7 & 12.8 & $<0.0001$ \\
\hline DPP-4 inhibitors & 21.2 & 22.5 & 12.1 & $<0.0001$ \\
\hline GLP-I receptor agonists & 3.6 & 8.6 & 2.7 & $<0.0001$ \\
\hline
\end{tabular}

Notes: Data are mean (standard deviation) or proportions (\%). P-value: Kruskal-Wallis tests.

and diabetologist care were significantly related to a lower odds of fractures, whereas heart failure was associated with a higher chance of experiencing $\geq 1$ fracture (Table 6).

\section{Discussion}

The results of this study indicate that initiation of insulin therapy in patients with type 2 diabetes is associated with an increased risk of fractures overall. Type 2 diabetes patients with oral antidiabetic agents had a $13 \%$ lower chance of

Table 6 Multivariate logistic regression model for developing any fractures in type 2 diabetes patients in primary care practices

\begin{tabular}{lll}
\hline Variables & $\begin{array}{l}\text { Odds ratio } \\
(\mathbf{9 5 \%} \mathbf{~ C l})\end{array}$ & P-value \\
\hline Glargine versus NPH basal insulin* & $0.69(0.50-0.96)$ & 0.0264 \\
Detemir versus NPH basal insulin* & $0.94(0.59-1.49)$ & 0.7842 \\
Male sex (yes/no) & $0.62(0.46-0.84)$ & 0.0021 \\
Diabetologist care (yes/no) & $0.26(0.16-0.43)$ & $<0.000$ I \\
Heart failure (yes/no) & $1.55(1.06-2.28)$ & 0.0237 \\
\hline
\end{tabular}

Notes: Final model after stepwise selection of all variables. *Minimum basal insulin treatment duration: 2 years.

Abbreviation: $\mathrm{Cl}$, confidence interval. having any fracture during an average of 2.5 years of followup compared to incident insulin users, although not statistically significant due to relatively few outcomes and short observation times.

The underlying mechanisms for this difference in fracture risk are not clear. A possible cause of the increased risk of fracture in insulin-treated type 2 diabetes is hypoglycemia, which may increase the risk of falling. Furthermore, diabetes-related comorbidity, such as diabetic retinopathy (disturbed vision) and peripheral neuropathy (problems with balance as well as neurological and musculoskeletal disabilities), may contribute to frequent falls to increase the risk of fractures. Although a higher bone mineral density has been found in type 2 diabetes compared to control subjects, a deterioration in bone microarchitecture and an inefficient distribution of bone mass in combination with insufficient repair and adaption mechanisms all lead to skeletal complications of diabetes. ${ }^{18}$ Factors circulating in the blood of type 2 diabetes patients may affect osteoblast function, for example, an increase of transforming growth factor- $\beta$ may be 
a pathogenic mechanism underlying poor bone formation. ${ }^{19}$ Thus, a combination of poor bone quality and more frequent falls due to hypoglycemia and increased diabetes-related comorbidity may increase the risk of fracture, in particular among insulin-treated type 2 diabetes patients. ${ }^{20}$

There was also an indication that conventional insulin treatment, which is carried out with premixed short and long-acting insulin, is related to an increased fracture risk compared to type 2 diabetes patients with BOT. Furthermore, a lower risk of any fracture was observed among insulin glargine users compared to NPH basal insulin. However, this lower chance was only observed after a longer treatment duration of at least 2 years.

It is conceivable that the lower risk of hypoglycemia in BOT $^{21-23}$ and glargine treatment ${ }^{24,25}$ mainly contributed to the lower chance of experiencing any fractures. Unfortunately, the prevalence of documented hypoglycemia was low in the Disease Analyzer database, which hampered the investigation of the impact of hypoglycemia on fracture risk in the present study. Hypoglycemia-induced falls are common in type 2 diabetes patients. ${ }^{26}$ The etiology of falls in type 2 diabetes is multifactorial, including microvascular complications and other age-related comorbidities, with hypoglycemia as a major underlying causal factor. ${ }^{26}$ In particular, insulintreated patients are more likely to experience falls during a hypoglycemic episode. ${ }^{27}$

In the present study, sulfonylurea prescriptions were also identified as an independent risk factor for fractures in one of the regression analyses (insulin vs OAD). Sulfonlyurea treatment is associated with an increased risk of hypoglycemia. ${ }^{28}$ However, the few studies on the link between sulfonylurea treatment and fall-related fractures yielded conflicting results and suffered from several methodological limitations. ${ }^{28}$ Thus, future studies are needed to investigate the relationship between sulfonylureas and fracture risk in type 2 diabetes.

In line with the present study, women with type 2 diabetes were more likely to develop fractures as a result of falls when compared with men in a previous investigation. ${ }^{29}$ In the Third National Health and Nutrition Examination Survey in the US, diabetes was also more frequently associated with slower walking speed, inferior lower-extremity function, decreased balance, and an increased risk of falling in women than in men. ${ }^{30}$

A known risk factor associated with the development of fractures is older age, which was also observed in the present study. ${ }^{31}$ Furthermore, heart failure was previously identified as a risk factor for fractures in the older population, which could be confirmed in the present study in older patients with type 2 diabetes. ${ }^{32}$ The relationship between peripheral arterial disease found in the present and previous studies may be due to lower bone mineral density. ${ }^{33}$ Finally, as a novel finding, diabetologist care was independently related to a lower chance of fractures in insulin-treated type 2 diabetes in the current investigation, which needs to be confirmed in further studies. Most likely, multiple factors, including a more intensive diabetes control and reduction of hypoglycemia contribute to the lower fracture risk.

Several limitations of the present study should be mentioned. First, no valid information on diabetes type and prescribed daily doses of medications were available in the database. Furthermore, no valid information on diabetes duration was provided. Also assessment of fractures and comorbidity relied on ICD codes by primary care physicians exclusively. It is noteworthy that the significantly reduced fracture risk among glargine compared to NPH users was found in a post hoc analysis taking into account a minimum insulin treatment duration of 2 years. This finding most likely reflects that insulin initiation and titration is a challenge in a number of type 2 diabetes patients during the first 1-2 years. Finally, measurements of $\mathrm{HbA}_{\mathrm{lc}}$ and BMI values were not standardized. The strength of the study is the large nationwide database and unbiased assessment of prescriptions.

In conclusion, initiation of insulin therapy in primary care patients with type 2 diabetes seems to be associated with an increased risk of fractures overall. The observed lower fracture risk in patients with BOT and long-term glargine therapy is most likely due to a lower risk of hypoglycemia-related falls, which needs to be investigated in future studies.

\section{Acknowledgment}

The authors disclose the receipt of the following financial support for the research, authorship, and/or publication of this article: the study was supported by an unrestricted grant from Sanofi-Aventis.

\section{Disclosure}

The authors report no conflicts of interest in this work.

\section{References}

1. Janghorbani M, Van Dam RM, Willett WC, Hu FB. Systematic review of type 1 and type 2 diabetes mellitus and risk of fracture. Am J Epidemiol. 2007; 166:495-505.

2. Janghorbani M, Feskanich D, Willett WC, Hu F. Prospective study of diabetes and risk of hip fracture: the Nurses' Health Study. Diabetes Care. 2006;29:1573-1578. 
3. Bonds DE, Larson JC, Schwartz AV, et al. Risk of fracture in women with type 2 diabetes: the women's health initiative observational study. $J$ Clin Endocrinol Metab. 2006;91:3404-3410.

4. Melton LJ 3rd, Leibson CL, Achenbach SJ, Therneau TM, Khosla S. Fracture risk in type 2 diabetes: update of a population-based study. J Bone Miner Res. 2008;23:1334-1342.

5. Grey A. Diabetes medications and bone. Curr Osteoporos Rep. 2015;13:35-40.

6. Monami M, Cresci B, Colombini A, et al. Bone fractures and hypoglycemic treatment in type 2 diabetic patients: a case-control study. Diabetes Care. 2008;31:199-203.

7. Ahmed LA, Joakimsen RM, Berntsen GK, Fonnebo V, Schirmer H. Diabetes mellitus and the risk of non-vertebral fractures: the Tromso study. Osteoporos Int. 2006;17:495-500.

8. Napoli N, Strotmeyer ES, Ensrud KE, et al. Fracture risk in diabetic elderly men: the MrOS study. Diabetologia. 2014;57:2057-2065.

9. Johnston SS, Conner C, Aagren M, Ruiz K, Bouchard J. Association between hypoglycaemic events and fall-related fractures in Medicarecovered patients with type 2 diabetes. Diabetes Obes Metab. 2012;14: 634-643.

10. Suissa S, Garbe E. Primer: administrative health databases in observational studies of drug effects - advantages and disadvantages. Nat Clin Pract Rheumatol. 2007;3:725-732.

11. Vestergaard P, Rejnmark L, Mosekilde L. Relative fracture risk in patients with diabetes mellitus, and the impact of insulin and oral antidiabetic medication on relative fracture risk. Diabetologia. 2005;48:1292-1299.

12. Rathmann W, Kostev K, Gruenberger JB, Dworak M, Bader G, Giani G. Treatment persistence, hypoglycaemia and clinical outcomes in type 2 diabetes patients with dipeptidyl peptidase- 4 inhibitors and sulphonylureas: a primary care database analysis. Diabetes Obes Metab. 2013;15:55-61.

13. Kowall B, Rathmann W, Kostev K. Are sulfonylurea and insulin therapies associated with a larger risk of cancer than metformin therapy? A retrospective database analysis. Diabetes Care. 2015;38:59-65.

14. Becher H, Kostev K, Schröder-Bernhardi D. Validity and representativeness of the Disease Analyzer patient database for use in pharmacoepidemiological and pharmacoeconomic studies. Int J Clin Pharm Therap. 2009;47:617-626.

15. Quan H, Sundararajan V, Halfon $P$, et al. Coding algorithms for defining co-morbidities in ICD-9-CM and ICD-10 administrative data. Med Care. 2005;43:1130-1139.

16. Swart E. Good practice of secondary data analysis, first revision. Gesundheitswesen. 2008;70:54-60.

17. Motheral B, Brooks J, Clark MA, et al. A checklist for retrospective database studies - Report from the ISPOR task force on retrospective databases. Value Health. 2003;6:90-97.

18. Oei L, Rivadeneira F, Zillikens MC, Oei EH. Diabetes, diabetic complications, and fracture risk. Curr Osteoporos Rep. 2015;13:106-115.

19. Ehnert S, Freude T, Ihle C, et al. Factors circulating in the blood of type 2 diabetes mellitus patients affect osteoblast maturation - Description of a novel in vitro model. Exp Cell Res. 2015;332:247-258.
20. Ivers RQ, Cumming RG, Mitchell P, Peduto AJ. Blue Mountains Eye Study. Diabetes and risk of fracture: the Blue Mountains Eye Study. Diabetes Care. 2001;24:1198-1203.

21. Holman RR, Thorne KI, Farmer AJ, et al. Addition of biphasic, prandial or basal insulin to oral therapy in type 2 diabetes. $N$ Engl J Med. 2007;357:1716-1730.

22. Janka HU, Plewe G, Riddle MC, Kliebe-Frisch C, Schweitzer MA, Yki-Järvinen H. Comparison of basal insulin added to oral agents versus twice-daily premixed insulin therapy for type 2 diabetes. Diabetes Care. 2005;28:254-259.

23. Bretzel RG, Nuber U, LandgrafW, Owens DR, Bradley C, Linn T. Oncedaily basal insulin glargine versus thrice-daily prandial insulin lispro in people with type 2 diabetes on oral hypoglycaemic agents (APOLLO) an open randomized controlled trial. Lancet. 2008;371:1073-1084.

24. Mullins P, Sharplin P, Yki-Järvinen H, Riddle MC, Haring HU. Negative binominal meta-regression analysis of combined glycosylated hemoglobin and hypoglycaemia outcomes across eleven phase III an IV studies of insulin glargine compared with neutral protamine Hagedorn insulin in type 1 and type 2 diabetes mellitus. Clin Ther. 2007;29:1607-1619.

25. Rosenstock J, Fonseca V, Schinzel S, Dain MP, Mullins P, Riddle M. Reduced risk of hypoglycemia with once-daily glargine versus twicedaily NPH and number needed to harm with NPH to demonstrate the risk of one additional hypoglycemic event in type 2 diabetes: evidence from a long-term controlled trial. J Diabetes Complications. 2014;28:742-749.

26. Malabu UH, Vangaveti VN, Kennedy RL. Disease burden evaluation of fall-related events in the elderly due to hypoglycemia and other diabetic complications: a clinical review. Clin Epidemiol. 2014;6:287-294.

27. Kennedy RL, Henry J, Chapman AJ, Nayar R, Grant P, Morris AD. Accidents in patients with insulin-treated diabetes: increased risk of low-impact falls but not motor vehicle crashes - a prospective registerbased study. J Trauma. 2002;52:660-666.

28. Lapane KL, Yang S, Brown MJ, Jawahar R, Pagliasotti C, Rajpathak S. Sulfonylureas and risk of falls and fractures: a systematic review. Drugs Aging. 2013;30:527-547.

29. Wallace C, Reiber GE, LeMaster J, et al. Incidence of falls, risk factors for falls, and fall-related fractures in individuals with diabetes and a prior foot ulcer. Diabetes Care. 2002;25:1983-1986.

30. Gregg EW, Beckles GL, Williamson DF, et al. Diabetes and physical disability among older U.S. adults. Diabetes Care. 2000;23:1272-1277.

31. Kroger H, Tuppurainen M, Honkanen R, Alhava E, Saarikoski S. Bone mineral density and risk factors for osteoporosis-a populationbased study of 1600 perimenopausal women. Calcif Tissue Int. 1994;55:1-7.

32. Jørgensen TS, Hansen AH, Sahlberg M, et al. Falls and comorbidity: the pathway to fractures. Scand J Public Health. 2014;42:287-294.

33. Hyde Z, Mylankal KJ, Hankey GJ, Flicker L, Norman PE. Peripheral arterial disease increases the risk of subsequent hip fracture in older men: the health in men study. Osteoporos Int. 2013;24:1683-1688.

Diabetes, Metabolic Syndrome and Obesity: Targets and Therapy

Dovepress

\section{Publish your work in this journal}

Diabetes, Metabolic Syndrome and Obesity: Targets and Therapy is an international, peer-reviewed open-access journal committed to the rapid publication of the latest laboratory and clinical findings in the fields of diabetes, metabolic syndrome and obesity research Original research, review, case reports, hypothesis formation, expert opinion and commentaries are all considered for publication. The manuscript management system is completely online and includes a very quick and fair peer-review system, which is all easy to use. Visit http://www.dovepress.com/testimonials.php to read real quotes from published authors. 